\title{
UMA 'VERDADEIRA RÉPLICA': CONSIDERAÇÕES ACERCA DA NOÇÃO DE AUTENTICIDADE NO CAMPO DO PATRIMÔNIO CULTURAL
}

\author{
Leticia Bauer*
}

\begin{abstract}
Resumo: O presente artigo tem por objetivo discutir alguns aspectos relativos à noção de autenticidade no campo do patrimônio cultural, em especial no que se refere aos remanescentes materiais do passado. A partir de pontos de vista diversos, propõe-se a relativização da oposição entre autêntico e inautêntico, buscando localizar nas cópias, reproduções e reconstruções pertinentes objetos de estudo para pesquisadores interessados nas temáticas associadas ao patrimônio cultural na contemporaneidade.
\end{abstract}

Palavras-chave: Autenticidade. Patrimônio cultural.

\begin{abstract}
This paper aims to discuss some aspects of the notion of authenticity in the cultural heritage field, especially regarding remaining materials of the past. From different points of view, it proposes to relativize the opposition between the authentic and inauthentic, seeking to locate in copies, reproductions and reconstructions, relevant objects of study to researchers interested in issues related to cultural heritage in contemporary society.
\end{abstract}

Keywords: Authenticity. Cultural heritage.

Parece ser um consenso que as temáticas relativas ao patrimônio cultural têm ocupado progressivamente mais espaço em seminários, encontros e currículos. Resenhas, resumos e artigos, exatamente como este que se inicia, partem desta constatação. Patrimônio ora figura como categoria, ora como tema ou área de estudo, acompanhado dos mais diferentes adjetivos. A discussão sobre o que constitui efetivamente o patrimônio de um grupo é longa e esta

* Doutoranda do Programa de Pós-graduação em História da Universidade Federal do Rio Grande do Sul (UFRGS) e bolsista CNPq. E-mail: lelebauer@hotmail.com 
suposta arbitrariedade eletiva é constante ponto de críticas por profissionais de diversas áreas, notadamente das Ciências Sociais. Todas as críticas são feitas, em maior ou menor grau, ao processo de investimento de valor realizado sobre determinado bem móvel, imóvel ou intangível, construído a partir de um lugar de fala autorizado e reconhecido. Geralmente essa perspectiva toma como objeto de análise ações que envolvem iniciativas governamentais ligadas, de diferentes maneiras, aos processos de tombamento de bens materiais ou salvaguarda de bens imateriais. Também é possível trabalhar com definições menos objetivas, que definem patrimônio cultural como algo construído em função da relação entre a carga simbólica acumulada por um bem ao longo do tempo e os novos usos e significações efetivados pelos indivíduos em relação a ele ${ }^{1}$, ou como um espaço de luta material e simbólica entre as classes, as etnias e os grupos. ${ }^{2}$

Em artigo intitulado O patrimônio como categoria de pensamento, José Reginaldo Gonçalves afirma: "discute-se a presença ou ausência do patrimônio, a necessidade ou não de preservá-lo, porém não se discute sua existência". ${ }^{3}$ Nesse artigo, o autor apresenta o 'patrimônio' como uma categoria de pensamento importante para a coletividade humana ${ }^{4}$ e identifica esta categoria em diferentes sociedades, avançando, assim, nas discussões que tratam o 'patrimônio' como uma construção exclusivamente ligada à modernidade ocidental. ${ }^{5}$

O ponto sobre o qual gostaria de me deter suscita debates acalorados, independentemente da área de conhecimento em que ocorrem. Suponho que, nas políticas contemporâneas de salvaguarda, conseguimos identificar mais claramente os limites do que as possibilidades das cópias, reproduções e reconstruções e, com isso, damos o aval ao autêntico sem considerações, ainda que breves, acerca das emulações de formas do passado.

Gostaria de inserir essa discussão no debate acerca das novas tecnologias, temática constantemente presente na pauta contemporânea sob perspectivas ora otimistas, ora pessimistas ao extremo. É aparentemente consenso que a tecnologia viabiliza uma capacidade nunca antes experimentada de proporcionar troca e produção de informação (tanto em quantidade, como em rapidez), bem como de tornar possível uma ação direta dos indivíduos sobre essa produção. Acredito que as tecnologias são instrumentos novos para serem utilizados em museus, arquivos e instituições voltadas para a salvaguarda de bens culturais de natureza material ou imaterial.

Bancos de dados, projeções, totens multimídia, museus virtuais, softwares para gerenciamento de acervos, passeios virtuais, instrumentos para proporcionar exatidão em processos de restauração... A lista de possibilidades seria longa e boa parte dessas opções já está presente em um número expressivo de instituições. Porém, acredito que restringir o avanço tecnológico ao caráter 
de 'novidade' ou 'modernização' em instituições como museus, arquivos e instituições vinculadas ao patrimônio cultural implica ignorar que esse processo, ao que tudo indica, sugere modificações mais profundas. Inicio com um breve relato.

Em maio de 2011 uma campanha lançada pela Intel ${ }^{6}$ arrebatou usuários do Facebook. ${ }^{7}$ Com o objetivo de promover a segunda geração de processadores i5, foi desenvolvido e disponibilizado um aplicativo que viabilizava a criação de um museu virtual com base nas informações, imagens e vídeos postados no Facebook de cada um dos usuários. Tratava-se do Museum of Me, iniciativa que criou milhares de exposições centradas na figura do usuário e seu 'acervo digital' concentrado nos álbuns virtuais do Facebook. A exposição virtual exibia uma museografia contemporânea e contava, inclusive, com visitantes imaginários em 3D.

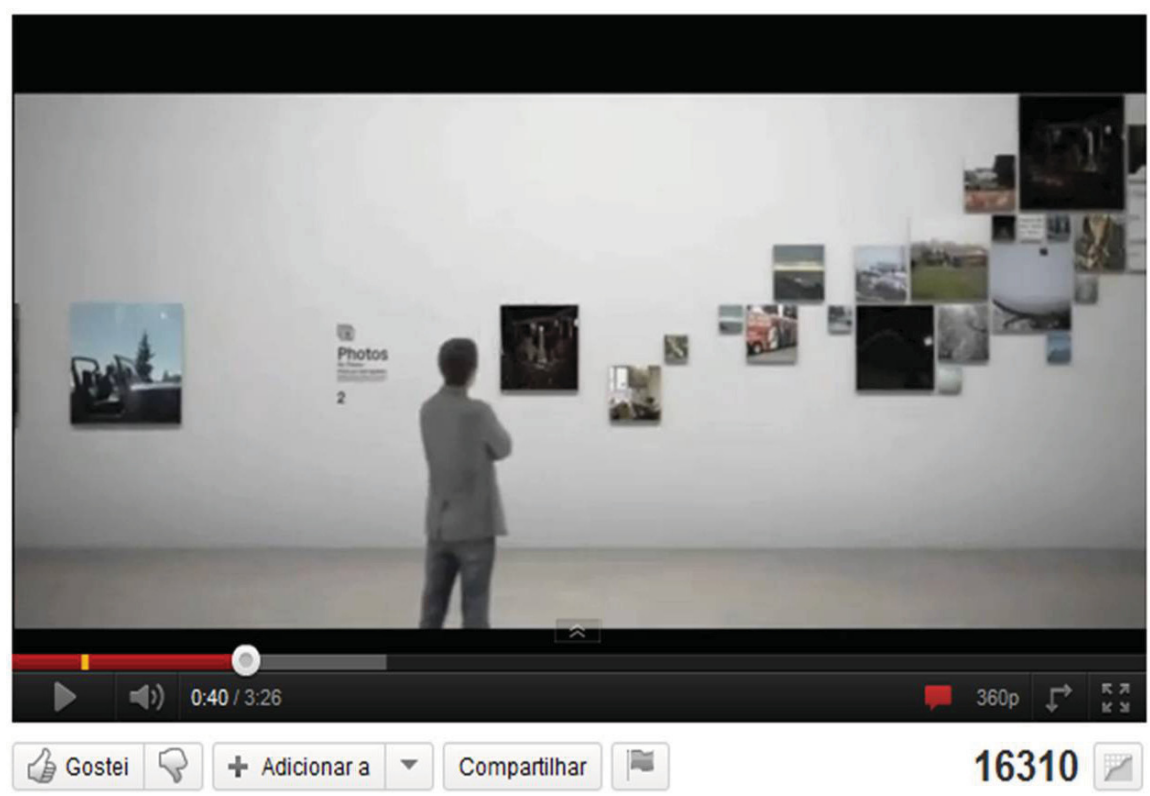

Exposição virtual criada a partir do Facebook de um usuário por meio do aplicativo Museum of Me e disponibilizada no Youtube.Disponível em: $<$ http://www.youtube. com/watch? $=\mathrm{C} 3 \mathrm{vQPjsCYag} \&$ feature=related $>$. Acesso em: 20 ago. 2011.

O protagonismo individual encontrou seu espaço no ambiente museológico. Virtual, por que não? Basta entrar no Youtube, esse grande arquivo de fontes para história do tempo presente, para visualizar museus virtuais pessoais de pessoas de diferentes países. Duas questões merecem destaque: em primeiro lugar, tudo na exposição era digital ('objetos' produzidos por câmeras digitais, scanners e câmeras de vídeo, bem como o museu, fisicamente inexistente); em segundo lugar, o museu, com todos os seus atributos e possibilidades, foi usado como meio para atrair consumidores. 
A recente publicação A questão dos livros: passado, presente e futuro, reunião de artigos de Robert Darnton publicada em $2010^{8}$, aborda questões sobre os livros na era digital e discute as possibilidades da digitalização dos acervos de grandes bibliotecas, democratizando o acesso universal aos usuários. O livro é, agora, duplicado e distribuído com a rapidez possibilitada por uma boa conexão, gerando um número incalculável de múltiplos. Roger Chartier, que também se dedicou ao tema, destaca: "a tela não é uma página, mas sim um espaço de três dimensões que possui profundidade e que nele os textos brotam sucessivamente do fundo da tela para alcançar a superfície iluminada. (...) no espaço digital, é o próprio texto, e não seu suporte, que está dobrado". ${ }^{9}$

Segundo Chartier, o que se coloca de imediato frente à textualidade eletrônica é a articulação aberta, fragmentada e relacional permitida pelos hipertextos. Mais que isso, as 'provas' fornecidas pelos historiadores por meio de rodapés, citações e referências podem ser consultadas pelo leitor. É possível acompanhar o percurso da pesquisa e refazê-lo, parcial ou totalmente, na medida em que podem ser disponibilizados documentos, imagens, registros de áudio e vídeo que foram utilizados para a produção de determinado conhecimento. ${ }^{10}$ Originais, em ambos os casos, não integram, em nenhum momento, o quadro de itens relevantes em cada uma das experiências.

Não são poucos os autores que se voltaram para o tema das novas tecnologias e as mudanças nas formas de vida e relacionamento no mundo contemporâneo. A cultura, tema afeito aos estudos do patrimônio cultural, experimenta novos significados. Segundo Lipowetsky, estamos na era da cultura-mundo. ${ }^{11}$ Para o autor, novas tecnologias e indústrias culturais e de comunicação tornaram "possível um consumo abundante de imagens e, ao mesmo tempo, a multiplicação dos canais, das informações e das trocas ao infinito". ${ }^{12}$ Mais que isso, ressalta o autor:

enquanto a arte (...) se alinha com as regras do mundo mercantil e midiático, as tecnologias da informação, as indústrias culturais, as marcas e o próprio capitalismo constroem, por sua vez, uma cultura, isto é, um sistema de valores, objetivos e mitos. O cultural de difrata enormemente no mundo material, que se empenha em criar bens impregnados de sentido, de identidade, de estilo, de moda, de criatividade, através de marcas, de sua comercialização e de sua comunicação. ${ }^{13}$

Partindo disso, não fica difícil inserirmos museus e outras instituições culturais nesse turbilhão. Museus espetaculares, criação de destinos para o turismo cultural, lojas repletas de produtos para venda: reproduções de obras 
de arte em suportes de boa qualidade, xícaras de chá reproduzindo padrões de faianças reais, brincos romanos à semelhança daqueles encontrados em alguma escavação, parques de temática 'histórica'. Cópias e reproduções de obras de arte e objetos antigos ocupam cada vez mais espaço no mercado, desde lojas de departamentos até boutiques alternativas. Em obras de arte reproduzidas em camisetas, cadernos e canecas, apresentam-se possibilidades infinitas de intervenção graças softwares e outros meios de manipulação de imagem. Os 'estilos de época', no que se refere à arquitetura, estão longe de serem abandonados. Uma rápida busca na internet com a expressão 'reprodução de obras de arte' fornece uma lista considerável de empresas que fornecem 'releituras' da melhor qualidade. ${ }^{14}$

Não é raro encontrarmos duras críticas ao turismo, suposto promotor de 'invenções' culturais. Aqui chegamos a um ponto crucial: ao mesmo tempo em que se superestima o autêntico, novas tecnologias abrem espaço para o uso/ consumo de cópias sem comparação no tempo. Longe de redigir um artigo a favor ou contra reproduções e reconstruções, gostaria de retomar alguns argumentos que integram diferentes pontos de vista (muitas vezes sobrepostos) sobre a noção autenticidade no campo do patrimônio cultural, particularizado, neste artigo, por vestígios materiais do passado.

\section{I.}

No âmbito do patrimônio cultural material, é inegável que a teoria que orienta processos de restauração tem um peso considerável na valorização da autenticidade, desdobrando-se em considerações acerca do valor artístico e histórico de vestígios materiais, bem como nas questões éticas que lhe são supostamente inerentes. Para Cesare Brandi ${ }^{15}$, teórico que é citado com frequência como referência para os processos de restauração desenvolvidos na atualidade, a noção de 'testemunho' é chave para o processo de restauração. Testemunhos históricos ou artísticos fortemente ligados a ideia de que a materialidade de vestígios do passado no presente é chave para a relação com o tempo pregresso. Partindo dessa premissa, é possível a questão: falsos objetos, falsos testemunhos?

Ao se referir à falsificação, Brandi atribui considerável peso à intenção. O que diferencia cópia, imitação e falsificação são intencionalidades diversas. Nesse sentido, a cópia e a imitação teriam como fim a documentação do objeto ou prazer que deles se poderia extrair, enquanto a falsificação tem como objetivo induzir ao erro. ${ }^{16}$ A teoria de Brandi, considerada crucial, inclusive para a redação da Carta de Veneza ${ }^{17}$, mesmo se detendo sobre temas como cópias, reconstruções e repristinações, é clara quanto à sua aplicabilidade: refere-se ao 
vestígio material foi produzido no passado, independentemente do investimento de valor de historicidade ou artisticidade realizado posteriormente.

Cópias, imitações e falsificações orbitam nas proximidades do múltiplo desprovido de verdade. Reconstruções são exemplos frequentes para discursos sobre falta de ética, não somente para com o público contemporâneo mas, principalmente, para com as gerações futuras. Essas situações não são estranhas aos técnicos que trabalham na área. A autenticidade desponta, nas atividades de preservação de bens materiais, como um dos itens extremamente relevantes para a designação de um patrimônio cultural.

Llorenç Prats, em livro intitulado Antropología y patrimonio, faz uso de uma imagem que considero interessante. No livro mencionado, o autor dedica um capítulo exclusivamente à discussão sobre patrimônio como recurso turístico e é nessa relação que a autenticidade entra como item relevante. A discussão sobre autenticidade possui estreito vínculo com as teorias contemporâneas da restauração de bens móveis e imóveis. Talvez não seja arriscado dizer que é muitas vezes, inclusive, condicionada pelas mesmas. Essas teorias constituem um saber específico e opõem-se veementemente a qualquer lugar comum que pressuponha que 'refazer tal qual o antigo' seja adequado. Não raro, ao longo das atividades de técnicos dedicados à preservação do patrimônio cultural, ocorrem debates que tem como ponto de discordância o 'parecer antigo'. Por outro lado, a noção de prova, caríssima também aos historiadores, pode ser aproximada dessa perspectiva. Afirma Prats:

Yo ignoro si la Gioconda que se expone en el Louvre es el original o una esmerada copia, pero sí hay dos cosas que me atrevo a afirmar con razonable convicción: que el conocimiento artístico que se transmite es el mismo y que las colas para contemplarla no se formarían si se tuviese la certeza de que se trataba de una copia. Parecen dos afirmaciones contradictorias, pero, al contrario, reflejan las dos realidades que confluyen en la obra de arte: sacralidad y conocimiento. ${ }^{18}$

Sou tentada a pensar que essa confluência mencionada por Prats não desfruta de igualdade e, no caso do patrimônio edificado, a ideia de autenticidade/ sacralidade é um dos pressupostos fundamentais. Réplicas são duramente criticadas, uma vez que são imitações sem o 'valor' do original. Vale mais o dado de que uma edificação possui a grande maioria de seus componentes ainda feita com materiais originais, de acordo com as técnicas da época de sua construção, que uma presumida totalidade representada por reconstruções contemporâneas. Chamo a atenção para a necessidade de informação sobre a 
autenticidade. ${ }^{19}$ Faz-se questão desta singularidade e reforçá-la para o público constitui um esforço, sempre consciente. Disso presume-se que 'ser original' importa mais que 'parecer original'.

Ao explorar esse tema, Prats estabelece a oposição entre metáfora e metonímia como item relevante para o entendimento da relação entre o remanescente e suas possíveis imagens. Para o autor:

La autenticidad (...) tiene que ver con el carácter simbólico del patrimonio. Los mecanismos de asociación mental que utiliza el simbolismo se refieren fundamentalmente a dos figuras: la metáfora y la metonimia. La primera, como es sabido, se basa en el principio de semejanza y la segunda en el de contacto o participación. La eficacia simbólica de la metonimia, en principio, es muy superior a la de la metáfora, en la misma proporción que la reliquia de un santo (o de un héroe) lo es a la imagen de aquel. En el ámbito del patrimonio, la noción de autenticidad se basa exclusivamente en la metonimia, es decir, se logra únicamente mediante aquellos elementos que se supone que realmente han estado en íntimo contacto o formado parte de los parámetros extraculturales que los legitiman (sean especímenes naturales, objetos históricos y/o pertenecientes al individuo genial, o frutos de la inspiración creativa). La metáfora (la imagen, la fotografía, la copia, la reproducción...) tiente una capacidad de evocación auxiliar, pero jamás alcanza a legitimar por sí misma un repertorio patrimonial. ${ }^{20}$

Por que o caco é mais representativo do que a réplica do vaso? Longe de responder a essa questão, vale ressaltar sua desnaturalização. Hartog nos fornece o contra-argumento ao citar o exemplo do Japão, cuja lógica de preservação/ restauração não tem efeito, na medida em que o privilégio é dado à atualização por meio da reconstrução periódica de edificações sagradas, por exemplo. As reconstruções são idênticas e realizadas de acordo com um calendário prédefinido. ${ }^{21}$ Restaura-se, portanto, a função e o uso, e não a estrutura material. ${ }^{22}$

O documento redigido na Conferência de Nara sobre a Autenticidade em Relação à Convenção Mundial do Patrimônio, realizada no Japão em 1994, avança neste sentido. Na publicação Orientações Técnicas para Aplicação da Convenção do Patrimônio Mundial, publicada em 2010, são citados os itens necessários para satisfazer as 'condições de autenticidade'.

A capacidade de compreender o valor atribuído ao património depende do grau de credibilidade ou de 
veracidade que se pode atribuir às fontes de informação relativas a esse valor. $\mathrm{O}$ conhecimento e a compreensão dessas fontes de informação, no que toca às características originais e subseqüentes do património cultural, e ao seu significado, constituem as bases necessárias para a avaliação de todos os aspectos da autenticidade. ${ }^{23}$

Desse relevante documento, ressalto o item a seguir:

No que diz respeito à autenticidade, a reconstrução de vestígios arqueológicos, ou monumentos, ou bairros históricos só se justifica em circunstâncias excepcionais. A reconstrução só é aceitável se tiver por base uma documentação completa e pormenorizada, não podendo ser, de modo algum, conjectural. ${ }^{24}$

Partindo destas considerações, acredito ser importante enfatizar, uma vez mais, a estreita relação entre restauração e a composição dos caracteres que são atualmente utilizados para definir 'patrimônio', imprimindo a todas as suas manifestações o peso da autenticidade, da antiguidade e da exemplaridade dos vestígios materiais. A ampliação da compreensão de cultura e de patrimônio, a exemplo da legitimação dos bens de natureza intangível acrescenta na discussão, porém parece estar longe de desestabilizar a predominância da materialidade no entendimento do que constitui patrimônio fora das áreas técnicas e academia.

\section{II.}

Gostaria de particularizar a discussão a seguir a partir da lógica em que a materialidade (objetos ou edificações) de outro tempo não constitui apenas prova das narrativas que orbitam em torno dela, mas, também, provas da existência do passado, conforme apontou David Lowenthal ao tratar dos vestígios materiais: um passado destituído de relíquias tangíveis, diz o autor, parece tênue demais para ser plausível. ${ }^{25}$ Convém lembrar que a materialidade geralmente inspira figuras de linguagem nas quais objetos e edificações personificam-se (testemunham e dialogam) ou contém algo tão imaterial como a memória. Enfatiza-se a ressalva: fragmentos não são processos, são resíduos de processos ${ }^{26}$ Esses fragmentos, segundo Lowenthal, juntamente com a memória e a história, são formas de vivenciar o passado e aceitar sua existência. ${ }^{27}$

A permanência material do passado por meio de sua inscrição no presente não garante sua inserção e sua definição sincrônica/ anacrônica na 
contemporaneidade: "só lhe atribuímos o seu valor de rastro, ou seja, de efeitosigno, ao nos afigurar o contexto de vida, o ambiente social e cultural, em suma (...), o mundo que, hoje, falta, por assim dizer, ao redor da relíquia" ${ }^{28}$ É o que também afirma Lowenthal, ao negar a imagem de "guia autônomo para épocas remotas" a um objeto ou vestígio físico. ${ }^{29}$ Segundo o autor, o passado tangível não tem vida própria. As relíquias são mudas e requerem interpretação para exprimir sua função. ${ }^{30}$ Entretanto, o vestígio material 'está presente'.

Lowenthal menciona diversos exemplos em que a ideia da experiência com os remanescentes é tida como mais esclarecedora, se é possível utilizar esta expressão, do que a leitura de narrativas históricas. A ideia de 'viagem no tempo' é corroborada pela organização cuidadosa de museus-casa e de sítios históricos, em um processo estimulado pelo progressivo interesse manifesto pelo público ligado ao turismo cultural. A ideia de que uma imagem vale mais que mil palavras pode ser recriada, nesse caso, como 'a experiência que vale mais que mil palavras'. Os museus, inclusive, tiram partido dessa oferta, tanto pela experiência que proporcionam, como pelo aporte 'verídico' que os objetos oferecem. O que ali está exposto parece, 'de fato', verdadeiro. O passado como experiência visual, oferecida por meio de imagens de livros, associa-se ao passado como experiência sensorial.

\section{III.}

É preciso que se reconheça, no vestígio, sua antiguidade; é necessário que o passado seja identificado como o tempo de procedência de um artefato ou edificação. Segundo Lowenthal, são três os processos que permitem essa identificação: envelhecimento (deterioração/desgaste), ornamentação e anacronismo. Este último, especialmente interessante, relaciona-se com a distância temporal e "transforma relíquias em emanações de uma era anterior". ${ }^{31}$ Curiosamente para o autor, entretanto, a existência de uma 'aura de antiguidade' não depende, necessariamente, da autenticidade do material por meio de seu vínculo com uma época cronologicamente distante:

Se os artefatos parecem antiquados, acreditamos que eles venham de um passado histórico. Eles podem ou não conservar suas funções originais (...), porém nenhum deles é construído atualmente, exceto como imitações do gênero tradicional. Telhados de sapé ainda são utilizados, e sua popularidade gerou cópias feitas de fibra de vidro à prova de fogo; no entanto, até mesmo o sapé simulado e novo exibe uma aura de antigüidade porque ele parece antigo. ${ }^{32}$ 
A partir dessa afirmação, suponho que outra forma de compreensão torna-se razoável, na medida em que incide sobre o poder da autenticidade sob perspectiva diversa. Nesse sentido, cópias, reproduções e emulações constituem, também, uma das formas de experiência com o passado. Forma diversa, mas não inválida.

Parecer antigo aciona no espectador sua compreensão de passado. Objetos originais, cópias, reproduções e, até mesmo, reconstruções, compõem o imaginário acerca do que é 'antigo', misturando-se a filmes e romances que tratam de 'personagens ou períodos históricos'. A autenticidade desfruta de um valor de matriz, de origem para emulações. A verossimilhança, ao invés de alinhar-se imediatamente com o falso, localiza-se numa zona intermediária onde uma determinada ideia de passado encontra lugar. Descartar o que não é 'autêntico' como objeto de atenção e pesquisa implica ignorar o apelo que tem a antiguidade como referência, independentemente de sua manifestação material.

Para além de um juízo pessoal sobre a relevância de algo ser autêntico ou cópia, fica claro que esta última desfruta, muitas vezes, de um predicado didático ao ser utilizada como meio para auxiliar no entendimento do que uma dia foi uma casa, um mural ou instrumento de trabalho, que o fragmento, por si só, não dá a ver. Junto a uma reprodução disponibilizada em um museu, como eticamente se espera, deverá constar um aviso informando ao espectador que não se trata de um objeto original. É neste breve espaço de tempo entre o primeiro olhar e a leitura do aviso que a autenticidade permanece como valor em suspenso. Decepcionado ou indiferente, o espectador seguirá sua visita e terá a oportunidade de adquirir reproduções de imagens e objetos visitados na exposição. A cópia retro-alimenta o autêntico, tornando, assim, ambos sobreviventes contemporâneos de nosso modo de relação com o passado.

\section{IV.}

Proponho, finalmente, somar um último elemento nas considerações até então apresentadas. José Reginaldo Gonçalves, em artigo de 1988, parte da ideias de Walter Benjamin sobre aura e reprodutibilidade técnica para argumentar acerca do que denomina de formas 'não-auráticas' de autenticidade. O autor desenvolve sua proposta a partir da ideia de que a presumida autenticidade de um patrimônio nacional é definida e identificada com a existência de uma 'nação real'. Essa crença, entretanto, varia social e historicamente. Isso é exemplificado pelo autor a partir dos exemplos da cidade brasileira de Ouro Preto e da norteamericana Colonial Williamsburg. Esta última foi totalmente reconstruída na segunda metade do século XX a partir de pesquisas de diversos especialistas e tornou-se objeto de amplas críticas por sua 'falta de autenticidade'. 
Contrapondo os dois casos, Reginaldo Gonçalves propõe deslocar a discussão entre autêntico e inautêntico para a ideia de uma forma não-aurática de autenticidade. Segundo o autor, a autenticidade não-aurática "em contraste com a autenticidade 'aurática', dispensa um vínculo orgânico com o passado: o aspecto da 'recriação' é nela mais forte que o aspecto da 'herança' ". ${ }^{33} \mathrm{~A}$ partir deste argumento, problematiza-se a crença de que os patrimônios culturais mantêm alguma relação orgânica e real com a identidade nacional e o passado da nação. ${ }^{34}$ A configuração de Colonial Williamsburg e de outros exemplos similares constituiria, para Gonçalves, um exemplo de patrimônio cultural na época de sua reprodutibilidade técnica. Diz o autor sobre as experiências de recriação:

Elas tornam explícito o caráter artificial, construído ou tecnicamente reproduzido, dos chamados patrimônios culturais. Sua autenticidade é 'não-aurática'. Ela está fundada não numa relação orgânica com o passado, mas na própria possibilidade de reprodução técnica. Desse modo, somos levados a problematizar categorias como as de nação, que supostamente, são expressas pelos chamados patrimônios culturais. ${ }^{35}$

V.

Ao nos colocarmos para além da oposição entre autêntico e inautêntico, em suas diversas variáveis, torna-se possível perceber que as relações com o patrimônio cultural também circulam pelo universo do múltiplo. Para além das possibilidades didáticas, torna-se viável afirmar que cópias, reproduções e reconstruções constituem desafio para pesquisa. Voltemos à internet.

A busca por sites que tratam da reprodução de obras de arte dá acesso a trechos como o transcrito a seguir:

Nossa técnica permite que você tenha em sua casa reproduções dos grandes mestres da pintura universal, com a mais alta fidelidade na reprodução e garantia de qualidade. Possuímos o maior acervo de obras do mundo, dos mais importantes pintores, como: Michelangelo, Claude Monet, Vicente Van Gogh, Picasso, Rembrandt, Joan Miró, Kandinsky, Renoir, Leonardo da Vince, entre outros. (...) Nossa movimentação comercial também está focada principalmente na internet, onde recebemos cerca de 3000 visitas diárias de diversos lugares do mundo. ${ }^{36}$ 
Ou, ainda:

REPRODUÇÃO de obra de arte hoje em dia utiliza-se de equipamentos sofisticados totalmente digitais e contam com um banco de imagens da obra original. A reprodução de um Van Gogh, um Klimt, um Renoir, Monet, El Greco e tantos outros mestres da pintura serão sempre feitas exatamente igual a obra original, e ainda por cima "pasmem" EM TELA DE PINTURA. Ou seja você tem uma verdadeira réplica da obra de arte. Este sistema é amplamente conhecido por Museus do mundo inteiro, que já utilizam amplamente esta técnica. (...) se você adora os eternos GRANDES MESTRES DA PINTURA Mas não tem milhões de dólares para investir. Conheça as reproduções em tela. Você vai adorar. $^{37}$

Importa ressaltar que tanto esses quanto outros anúncios deixam muito claro que o processo envolve reinterpretação, afastando-se peremptoriamente da ideia de falsificação. Mais um motivo para tornar-se interessante.

Na mesma incursão pelo ciberespaço, encontrei uma reportagem online do jornal $O$ Globo dedicada exclusivamente ao tema das lojas de museu. Sob o título de $O$ apelo irresistivel das lojas de museu $^{38}$, a autora do artigo apresenta e detalha várias lojas de museus de diferentes países:

Os museus do Vaticano, por exemplo, padronizaram as vendas: seja na Capela Sistina ou nas galerias ligadas à Basílica de São Pedro, você encontra lojas oficiais ou estandes com os mesmos produtos e preços. São chaveiros, abridores de carta, suvenires religiosos (como medalhas, orações em diversos idiomas, terços e que tais), cópias de documentos históricos e um grande acervo de jóias e semijóias. ${ }^{39}$

Um site sugerido na mesma matéria concentra numerosas lojas online de renomados museus franceses. ${ }^{40}$ Muitas inspirações, várias cópias, numerosos artigos contemporâneos que evocam o passado. Cada museu disponibiliza produtos que se relacionam especificamente com seus acervos e atendem aos desejos de consumo de seus visitantes.

Para além de uma apreciação pessoal, suponho que entender reproduções e cópias como objetos de estudo liga-se, direta ou indiretamente, aos processos de compreensão de remanescentes materiais do passado como patrimônios culturais contemporâneos. 
Como podemos resistir a esse universo declaradamente copiado do passado? Não podemos, nem devemos. Ao voltarmos nossa atenção para esse universo 'paralelo', 'fake', por assim dizer, estamos de frente para nós mesmos. É possível ser de outra forma?

\section{NOTAS}

1 DURHAM, Eunice. Cultura, patrimônio e preservação - Texto II. In: ARANTES, Antonio Augusto (Org.). Produzindo o passado: estratégias de construção do patrimônio cultural. São Paulo: Brasiliense, 1984. p. 30-31.

${ }^{2}$ CANCLINI, Nestor Garcia. O patrimônio cultural e a construção imaginária do nacional. Revista do Patrimônio Histórico e Artístico Nacional, Rio de Janeiro, n. 23, p. 95-115, 1994, p. 97.

${ }^{3}$ GONÇALVES, José Reginaldo Santos. O patrimônio como categoria de pensamento. In: ABREU, Regina; CHAGAS, Mário (Orgs.). Memória e patrimônio: ensaios contemporâneos. Rio de Janeiro: Lamparina, 2009. p. 28.

${ }^{4}$ GONÇALVES, José Reginaldo Santos. Op. Cit., p. 26.

${ }^{5}$ Segundo o autor, "A categoria 'colecionamento' traduz, de certo modo, o processo de formação de patrimônios. Sabemos que esses, em seu sentido moderno, podem ser interpretados como coleções de objetos móveis e imóveis, apropriados e expostos por determinados grupos sociais. Todo e qualquer grupo humano exerce algum tipo de colecionamento de objetos materiais, cujo efeito é demarcar domínio subjetivo em relação ao 'outro'. O resultado dessa atividade é precisamente a constituição de um patrimônio”. Ibidem, p. 26.

${ }^{6}$ Empresa internacional que produz diversos produtos ligados à informática.

${ }^{7}$ Essa rede social virtual conta com cerca de 600 milhões de usuários no mundo até o início de 2011.

${ }^{8}$ DARNTON, Robert. A questão dos livros: passado, presente e futuro. São Paulo: Companhia das Letras, 2010.

9 CHARTIER, Roger. Os desafios da escrita. São Paulo: Editora UNESP, 2002. p. 31.

${ }^{10}$ CHARTIER, Roger. A história ou a leitura do tempo. Belo Horizonte: Autêntica Editora, 2010. p. 59-60.

11 "Cultura-mundo significa o fim da heterogeneidade tradicional da esfera cultural e a universalização da cultura mercantil, apoderando-se das esferas da vida social, dos modos de existência, da quase totalidade das atividades humanas. Com a cultura-mundo, dissemina-se em todo o globo a cultura da tecnociência, do mercado, do indivíduo, das mídias, do consumo; e, com ela, uma infinidade de novos problemas que põem em jogo questões não só globais (ecologia, imigração, crise econômica, miséria do Terceiro Mundo, terrorismo...) mas também existenciais (identidade, crenças, crise dos sentidos, distúrbios da personalidade...). A cultura globalitária não é apenas um fato; é, ao mesmo tempo, um questionamento tão intenso quanto inquieto de si mesma. Mundo de que se torna cultura, cultura que se torna mundo: uma culturamundo". LIPOVETSKY, Gilles. A cultura-mundo: resposta a uma sociedade desorientada. São Paulo: Companhia das Letras, 2011. p. 9. 
${ }^{12}$ Ibidem, p. 10.

${ }^{13}$ Ibidem, p. 10-11.

${ }^{14}$ A expressão releitura aparece frequentemente nos sites, provavelmente devido à preocupação com a criminalização ligada à falsificação de obras de arte.

${ }^{15}$ BRANDI Cesare. Teoria da restauração. Cotia: Ateliê Editorial, 2004.

${ }^{16}$ Ibidem, p. 115.

${ }^{17}$ Carta Internacional sobre a Conservação e Restauro de Monumentos e Sítios, publicada em 1964.

${ }^{18}$ PRATS, Llorenç. Antropología y patrimonio. Barcelona: Ariel, 2004. p. 65.

${ }^{19}$ Os critérios de intervenção arquitetônica tomam como base a marca distintiva entre o que é original e o que foi realizado em épocas posteriores. A intervenção descontextualizada poderia ser assemelhada à execução de uma partitura de Mozart na qual faltam algumas notas apagadas no original. Colocar elementos descontextualizados seria como colocar notas à revelia na partitura clássica. Ao mesmo tempo, o novo deve indicar sua condição sem ficar dissonante da totalidade da obra.

${ }^{20}$ PRATS, Llorenç. Op. cit., p. 54-55.

${ }^{21}$ HARTOG, François. Tempo e patrimônio. Vária História, Belo Horizonte, v. 22, n. 36, 2006, p. 267.

${ }^{22}$ Seria interessante ressaltar as considerações da UNESCO sobre a diversidade cultural e a autenticidade do patrimônio cultural: "Os juízos sobre os valores atribuídos ao património cultural, bem como a credibilidade das fontes de informação, podem diferir de cultura para cultura, e mesmo dentro de uma mesma cultura. O respeito que é devido a todas as culturas exige que o património cultural seja considerado e julgado essencialmente nos contextos culturais a que pertence". UNESCO. Orientações Técnicas para a Aplicação da Convenção do Património Mundial. Lisboa: [s.e.], 2010, p. 29.

${ }^{23}$ Idem.

${ }^{24}$ Ibidem, p. 30.

${ }^{25}$ LOWENTHAL, David. Como conhecemos o passado. Projeto história [PUC-SP], São Paulo, n. 17, nov. 1998, p. 163. Importante ressaltar que tanto Brandi como Lowenthal, ambos citados neste artigo, trataram de bens materiais que nem sempre ostentam, necessariamente, o título de patrimônio cultural em qualquer uma de suas instâncias oficiais. Entretanto, partese do pressuposto que tanto as obras de arte quanto remanescentes materiais do passado são associados aos valores tratados pelos dois autores.

${ }^{26}$ Ibidem, p. 66.

${ }^{27}$ Idem.

${ }^{28}$ RICOEUR, Paul. Tempo e narrativa. Campinas: Papirus, 1994. p. 320-321.

${ }^{29}$ LOWENTHAL, David. Op. cit., p. 149.

${ }^{30}$ Ibidem, p. 157.

${ }^{31}$ Ibidem, p. 154. 
${ }^{32}$ Ibidem, p. 155.

${ }^{33}$ GONÇALVES, José Reginaldo. Autenticidade, Memória e Ideologias Nacionais: o problema dos patrimônios culturais. Estudos Históricos, Rio de Janeiro, v. 1, n. 2, 1988, p. 269.

${ }^{34}$ Idem.

${ }^{35}$ Ibidem, p. 273.

${ }^{36}$ Disponível em: <http://www.oleografia.com.br/site/quemsomos.asp >. Acesso em: 16 ago. 2011.

${ }^{37}$ Disponível em: <http://cassiobertazzoni.blogspot.com/2011/01/reproducao-ou-releitura. html >. Acesso em: 16 ago. 2011.

${ }^{38}$ BORGES, Ana Lúcia. O apelo irresistível das lojas de museu. Disponível em: $<$ http://oglobo. globo.com/viagem/mat/2008/11/19/o_apelo_irresistivel_das_lojas_de_museu-586476493. asp>. Acesso em: 16 ago. 2011.

${ }^{39}$ Idem.

${ }^{40}$ Disponível em: <http://www.boutiquesdemusees.fr/fr/>. Acesso em: 16 ago. 2011. 